Biological Activity of Compounds in Homologous Series

WHEN a biological action may be attributed to a physical mechanism, the equi-effective (equi-toxie, equi-riarcotic, etc.) concentrations of compounds in homologous series decrease very rapidly as the number of carbon atoms increases: the molar concentration required to pro-
duce a given effect is approximately one third that of the preceding
member; that is, the logarithm of the equi-ellective concentration member; that is, the logarithm of the equi-eilective concentration holds fairly well over a wide range of biological actions and homologous series, and it has been used to predict the activity of higher members of a series from results obtained with the lower homologues ${ }^{1}$. The decrease in equi-effective concentration does not, however, proceed indeflnitely. As the homologous series is ascended, a member is reached which has the maximum activity, and the higher members are either entirely inactive or have very greatly reduced activity. The position of this 'cut-off' depends on the homologous series, on the nature of the biological action being investigated, and even on the relative resistance of diferent strains of the same organism ${ }^{2}$. It is the purpose of this communication to suggest that the position of with lower homologues.

Ferguson ${ }^{3}$ has suggested the (thermodynamic) activity as defined by G. N. Lewis ${ }^{4}$ instead of concentration, as a more useful index of biological activity. He has shown that, as a homologous series is ascended, the equi-effective thermodynamic activity changes much more slowly than does the corresponding equi-effective concentration. Moreover, while the concentration decreases, the thermodynamic activity, in general, slowly increases (see Tables 2, 3 and 4 of ref. 3 ). This means that, although a rapidly diminishing concentration suffices to produce a given biological effect, a slowly increasing thermodynamic activity is needed. Since by definition the thermodynamic activity cannot exceed unity (which occurs when the solution becomes saturated), the member of the homologous series for which the thermodynamic activity approaches unity possesses the maximum biological activity. After that member the "cut-off' occurs, for a more than saturated solution would be needed to produce a given effect.

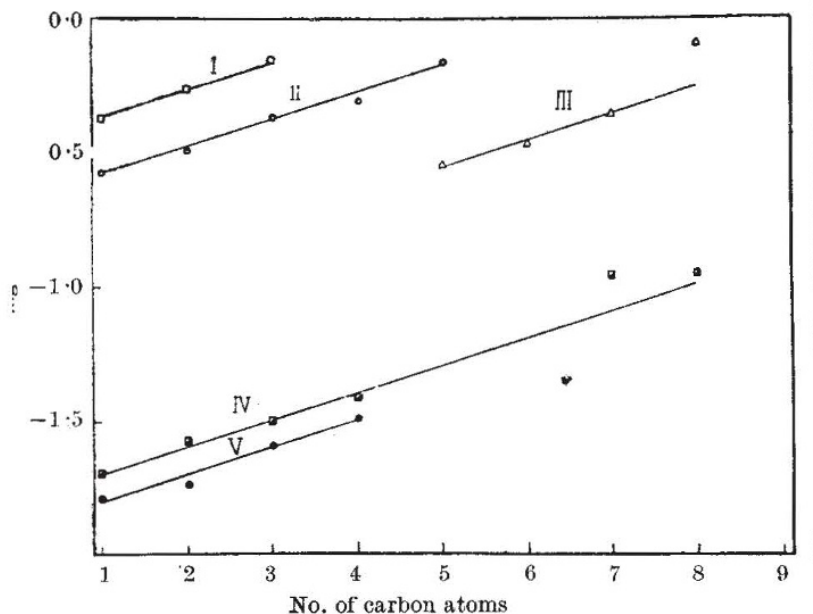

RELATIONSHIP BETWERN THE LOGARITHM OF THE THERMODYNAMIC ACTIVITY REQUIRED FOR EQOI-EFFECTIVE BIOLOGICAL ACTION, AND THE LENGTH OF CARBON CHAIN

I. Alkyl acetates : hæmolysis of ox blood.

II. Alcohols : bactericidal action, Staphylococcus aureus.

III. Paraffin hydrocarbons: narcosis of mice.

IV. Alcohols; inhibition of development of sea-urchin eggs.

v. Alcohols : tadpole narcosis.

It can be seen from the accompanying graph that for every additional $\mathrm{CH}_{2}$ group in any homologous series there is an approximately constant increase in the logarithm of the critical thermodynamic activity which just suffices to produce a given effect. This increase is followed fairly closely in the eight series calculated by Ferguson ${ }^{3}$, and in four additional ones which I have calculated from published biological results ${ }^{5,6}$. The average increase in $\log a$ for every additional $\mathrm{CH}_{2}$ group is $0 \cdot 10$. The divergencies do not appear to be greater than the probable error although the lower alcohols are sometimes, but not always, more active than could be predicted from the higher homologues. If, therefore, the logarithm of this critical thermodynamic activity can be calculated from the biological results obtained with the lower members, a straight line, drawn through these points at the average slope, will, when produced, give the member for which log $a$ approaches zero. In other words, this will give the member which will exert the same biological action as the lower members at a thermodynamic activity approaching unity. From Curve I, one can predict that, whereas concentration required in the case of propyl acetate, amyl acetate will probably be inactive under the same conditions. In fact, butyl acetat is active at about the required concentration? ${ }^{7}$ but no results were reported for amyl acetate. From Curve II one can expect heptyl alcohol to be inactive against Staphylococcus aureus, and hexyl alcohol probably active. 'Tilley and Schaffer ${ }^{5}$ found the 'cut-off' to occur with 'cut-off' does not oecur until later in the series. There are few biological results available with homologous series extending past octyl. Clark's results on the depression of the frog's heart are too approximate for accurate prediction, for all the molar concentrations above $\mathbf{C}_{s}$ are given to one signiflcant figure only. However, using the results of the three lower members, one can predict that the 'cut-off' should appear with hexadecyl alcohol. Clark found it to occur with tetradecyl alcohol.

It is a pleasure to thank Dr. J. C. Speakman for advice and criticism.

$$
\text { G. M. BADGER }
$$

Department of Chemistry

${ }^{1}$ Kamm, O., Science, 54, 55 (1921).

Schaffer, J. M., and Tilley, F. W., J. Bact., 14, 259 (1927)

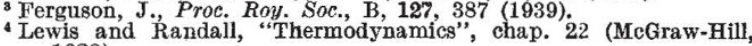
1923).

Tilley, F. W., and Schaffer, J. M., J. Bact, 12, 303 (1926)

elch, H., and Slocum, G. G., J. Lab. Clin. Med., 28, 1440 (1943) Vernon, H. M., J. Physiol., 43, 325 (1911). Fühner, H., Biochem. $Z ., 120,143$ (1921).

'Fühner, H., and Neubauer, E., Arch. exp. Path. Pharm., 56, 333 (1907). ${ }^{8}$ Clark, A. J., Arch. Int. Pharmacodyn., 38, 101 (1930).

\section{Effect of Electrolytes on Cation-active Detergents}

IT is well known that the addition of divalent metallic ions greatly enhances the surface-active properties of anion-active detergents, and it was suggested by Robinson ${ }^{1}$ that a similar effect should occur on adding divalent anions to cation-active substances. This was confirmed
by Powney and Addison ${ }^{2}$ for the addition of sulphate ions to dodecyl pyridinium chloride.

We have recently investigated the effect of the addition of sodium sulphate to several such compounds, including cetyl trimethyl ammonium bromide. It was found that in $0.01 \mathrm{~N}$ sodium sulphate, a concentration of 0.0025 per cent of this substance produced the maximum lowering of surface tension, whereas in the absence of added electrolyte a concentration of 0.015 per cent was necessary in order to produce the same effect.

Since cetyl trimethyl ammonium bromide is used as an antiseptic, tests were carried out to determine whether the bactericidal and penetrating properties of very dilute solutions would be improved by the addition of sodium sulphate. The test organism used was a pyogenic strain of Staphylococcus aureus supplied by the National Collection of Type Cultures, and it was found that by the addition of cetyl trimethyl ammonium bromide required to produce a given effect could be halved.

We would like to thank the Director of Research for his advice and criticism in this work, and the Council of the British Laundererg' Research Association for permission to publish this note.

$$
\begin{aligned}
& \text { British Launderers' Research Association, } \\
& \text { The Laboratories, } \\
& \text { Hill View Gardens, } \\
& \text { Hendon, N.W.4. } \\
& \text { Sept. 23. } \\
& \text { ' Nature, 139, } 626 \text { (1937). } \\
& \text { 2 Trans. Farad. Soc., 33, } 1253 \text { (1937). }
\end{aligned}
$$

JOHN A. HILL C. L. F. HUNTER

\title{
Reduction by Dissolving Metals
}

IN order to draw general conclusions as to the mechanism of reduction by dissolving metals from the data obtained in the course of a number of reductions by sodium and alcohol in liquid ammonia ${ }^{1,2,8}$, it is necessary to deternine more precisely the role of the solvent. That its use is not essential tor the hydrogenation of benzene derivatives to ar-dihydro-compounds is shown by the fact that anisole, dimethylanitine or $m$-tolyl methyl ether when treated in boilling light petroleum (b.p. 100-120 with potassium and the equivalent amount of ethyl, or better, isopropyl alcohol, gave the dihydro-derivatives already obtained,. This was shown by conversion to the 2:4-dinitrophenylhydrazone of $\Delta^{3}$-cyclohexenone, m.p. $133-134^{\circ}$, convertible by acid to the derivative of $\triangle^{2}$-cyclohexenone, m.p. $167^{\circ}$, and in the last case by preparation of the $2: 4$-dinitrophenylhydrazone of 3-methyl$\Delta^{2}$-cyclohexenone, m.p. $174^{\circ} \mathrm{s}$. The method has little practical value because of the small yields, except perhaps with compounds insoluble in ammonia; but it demonstrates that the solvent does not affect the nature of the products.

The favourable influence of ammonia is probably due partly to its ability to dissolve alkali metals, but more to its ability to stabilize the divalent anions formed as intermediates ${ }^{2}$ (compare its use for the preparation of alkali salts of very weak acids such as unsaturated hydrocarbons ${ }^{4}$ ). Also, in contrast to reduction in pure alcohols, both these methods employ much iower proportions of alcohol to substrate, thus increasing the effici
to form hydrogen gas.

The Dyson Perrins Laboratory,

Arthor J. Birch

1 Birch, $J$. Chem. Soc., 430 (1944).

Birch, J. Chem. Soc., 809 (1945).

${ }^{3}$ Birch, J. Chem. Soc., 593 (1946).

Levy and Cope, J. Amer. Chem. Soc., 66, 1684 (1944). Birch, unpublished work. 